Working Paper n. 14 - 2011

\title{
THE EFFECTIVENESS OF REMEDIAL COURSES IN ITALY: A FUZZY REGRESSION DISCONTINUITY DESIGN
}

\author{
Maria De Paola \\ Dipartimento di Economia e Statistica \\ Università della Calabria \\ Ponte Pietro Bucci, Cubo 1/C \\ Tel.: +390984 492459 \\ Fax: +390984 492421 \\ e-mail: m.depaola@unical.it
}

\author{
Vincenzo Scoppa \\ Dipartimento di Economia e Statistica \\ Università della Calabria \\ Ponte Pietro Bucci, Cubo 1/C \\ Tel.: +390984 492464 \\ Fax: +390984 492421 \\ e-mail: v.scoppa@unical.it
}

\section{Novembre 2011}

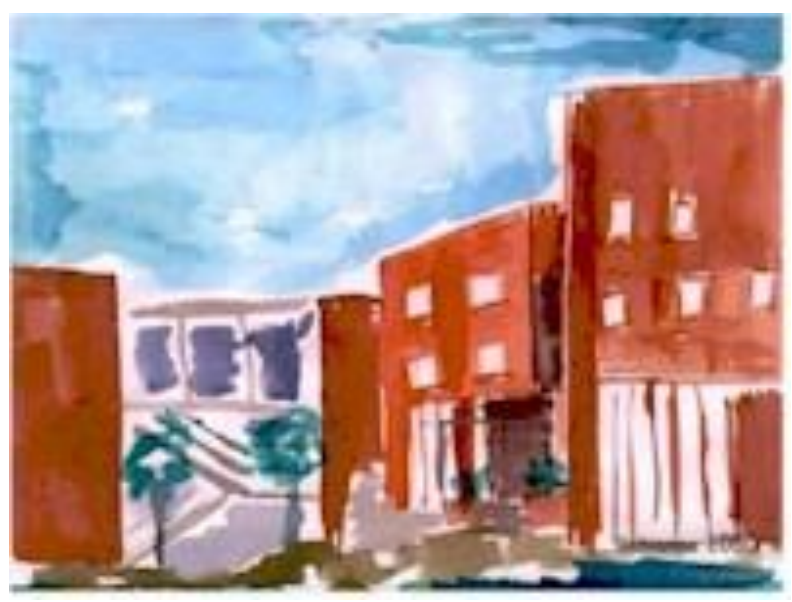




\title{
The Effectiveness of Remedial Courses in Italy: A Fuzzy Regression Discontinuity Design
}

\author{
Maria De Paola, Vincenzo Scoppa* \\ Department of Economics and Statistics, University of Calabria
}

$23 / 11 / 2011$

\begin{abstract}
We evaluate the effects on student achievement of a number of remedial courses provided by an Italian University. To identify the causal effect of remediation we use a Fuzzy Regression Discontinuity Design, relying on the fact that students whose performance at a placement test was below a certain cutoff were assigned to the treatment. We deal with partial compliance using the assignment rule as an instrumental variable for the effective attendance to remedial courses. From our analysis it emerges that students just below the cutoff, attending the remedial courses, acquire a higher number of credits compared to students just above the cutoff. We also find that remedial courses reduce the probability of dropping out from academic career. On the other hand, we do not find any statistically significant effect on the average grade obtained at passed exams.
\end{abstract}

JEL Classification: I23; I21; I28; C26; J24.

Keywords: Remedial Courses; Tertiary Education; Public Policy; Fuzzy Regression Discontinuity Design; Instrumental Variables

\section{Introduction}

Remedial courses are aimed at providing to underprepared students the skills necessary to college education. They should allow the whole body of students to develop the minimum skills needed to undertake college level courses and then to balance disparities generated in primary and secondary education.

Approximately one-third of US university students are required to take remedial courses in basic skills such as reading, writing or mathematics (Calcagno and Long, 2010). While remediation represents an important feature of higher education in US, it is much less common in European countries. Nevertheless, an increasing number of European universities have started recently to offer remedial programs. In Italy, for example, since the 2001 reform of the University system, universities

\footnotetext{
* Department of Economics and Statistics, University of Calabria, 87036 Arcavacata di Rende (CS), Italy. Email: m.depaola@unical.it; v.scoppa@unical.it. We are grateful to the administration of the University of Calabria for providing access to the data, to Sara Laurita, Antonella Caparelli and Alessandro Sole for assisting in the use of the data. We would like to thank Domenico Cersosimo, Piero Cipollone, Guido de Blasio, Federica Demaria, Marco Debenedetto, Francesca Gioia, Michela Ponzo and seminar participants at the University of Calabria for useful suggestions and comments.
} 
have to test freshmen students' skills in relation to the requirements necessary for the chosen degree course and any gap (the so called "debits") has to be filled. At this purpose, many Italian Universities, at the beginning of each academic year, organize courses at the pre-university level, which should enable students to begin their university career with an adequate level of competences.

Despite of their increasing diffusion, remedial courses are controversial. Some opponents argue that they drain resources, both in terms of money and time, towards students who are ill-suited for college. Others claim that placement into remediation may negatively impact student outcomes due to social stigma and negative effects on self-esteem and educational expectations. Critics are also concerned about the significant costs of remediation and argue that taxpayers already pay for educational opportunities financing secondary education. Finally, little is known about their effectiveness, since most colleges do not perform systematic evaluations of their programs.

Only few works have attempted to evaluate the effects of remediation on students' academic performance or labor market outcomes. Estimating the impact of remedial courses is not straightforward as the assignment of students to these courses is not random. Typically, students are assigned to remedial courses in relation to some measure of their abilities, such as their secondary education curriculum. As a result, students of lower ability are typically required to take remedial courses. This introduces a bias in those evaluations that try to measure the effectiveness of these courses by simply comparing the performance obtained by participating students with the performance of students not involved in these programs. In fact, it is not sufficient to control for individual characteristics, since the selection of students into the program is not only determined by observable variables (conditional independence assumption), but it is also influenced by unobservable characteristics that might be related to the outcome, giving rise to endogeneity problems. For instance, not all the students who are required to take remedial courses effectively undertake them. Problems of self-selection can lead both to an upward bias (for example, when only highly motivated students attend the courses) or to a downward bias (when courses are attended only by students with worse unobservable abilities) making it difficult to recover the effective impact of remediation on student achievement.

Some recent empirical studies have undertaken a variety of estimation strategies to handle these problems and to evaluate the effectiveness of remedial courses on outcomes such as performance in academic courses, probability of graduation and labor market earnings. Bettinger and Long (2009) analyse the effect of remediation in Ohio using an instrumental variable strategy, which relies on the importance of distance from university for student's college choice combined to the fact that in this State remediation assignment rules differ across universities. They show that remedial classes produce beneficial effects: remedial students are more likely to persist in college and to complete their educational program compared to students with similar characteristics who did not take the courses. 
Martorell and McFarlin (2010) and Calcagno and Long (2010) undertake an estimation strategy based on a Regression Discontinuity Design (RDD) exploiting the fact that in the States they consider, respectively Texas and Florida, remedial placement is decided on the basis of the score students obtain in a placement exam. Martorell and McFarlin find that remediation has little effect on a wide range of educational and labor market outcomes, while Calcagno and Long find that remediation promotes early persistence at college but does not produce positive effects on degree completion and on the number of college credits acquired by students. ${ }^{1}$

In this paper, using an approach similar to that used by Martorell and McFarlin (2010) and Calcagno and Long (2010), we present new evidence on the effects of remedial courses on the achievement of college students in Italy. At the best of our knowledge, there are no other works investigating the effects of remediation in European countries. ${ }^{2}$

We exploit data on about 4,000 freshmen enrolled in the academic year 2009/2010 at the University of Calabria, an Italian medium sized public University. Thanks to a project promoted by the regional government of Calabria and financed by the European Social Fund, students who were not considered ready to attend university courses were placed on remedial classes aimed at improving their basic skills. The remedial courses, consisting in 160 hours of lectures, were carried out at the beginning of the academic year and have covered both mathematics and language skills. Assignment to remedial courses was based on the results obtained by the students at a placement test: only students who, in each field of study, were placed below a certain score were required to take remediation courses. Courses were highly recommended but were not compulsory and, as a consequence, compliance of students to the assignment rule was not perfect.

Thanks to the cutoff rule adopted to assign students to the treatment it is possible to assess the effects of the program using a Fuzzy Regression Discontinuity Design (RDD) and considering as an instrument for the effective attendance of remedial courses the assigned treatment through the cutoff rule. Due to some randomness in the scores obtained at the placement test, students close to the cutoff are academically equivalent and then any jump in the relationship linking academic performance to student placement test score close to the cutoff can be taken as evidence of a treatment effect.

We evaluate the effectiveness of remedial courses considering some measures of student academic performance after two years of college: the number of credits earned by students, the probability of dropping-out from university and the average grade obtained at passed exams.

\footnotetext{
${ }^{1}$ A number of other papers have focused on remedial programs in compulsory education. For example, Jacob and Lefgren (2004), investigating the effects on student achievement of a remedial intervention implemented in Chicago public schools, show a positive effect on the academic achievement of third-graders, but not of sixthgraders. Lavy and Schlosser (2005) analyse the impact of a remedial intervention for underperforming high school students in Israel and find a significant increase in the school matriculation rate of participating students.

${ }^{2}$ One exception is Lagerlöf and Seltzer (2009) who, using a small sample from a UK Department, analyse the effects of remedial courses in Mathematics on the learning of Economics finding no positive effects.
} 
After controlling for partial compliance, treated students gain a higher number of credits with respect to students just above the threshold and face a lower probability of dropping out from academic career. On the other hand, we do not find any statistically significant effect on the grades obtained at passed exams.

It is worthwhile to notice that compared to similar previous works our analysis improves in a number of directions. Firstly, as students were not allowed to retake the placement test, we do not have to deal with problems deriving from the fact that unobserved factors may influence the likelihood of passing the remedial cutoff after retesting. Secondly, since we have information on the exact number of hours of remedial courses attended by each student, we accurately measure the intensity of treatment, avoiding problems that may derive from students that enroll to remedial courses but do not effectively attend the whole program. Finally, given the Italian institutional setting, our estimates do not suffer from biases arising from the selection of different courses, characterized by different levels of difficulty, by treated and control students. In fact, students in our sample were required to choose their subject of study before the placement test and they were not allowed to change this choice. In addition, the courses considered to evaluate students' performance were compulsory as students are not permitted to choose courses during their first year of degree program.

The paper is organized as follows. In Section 2 we provide some information on the Italian university system, describe the remedial program and the data used in the empirical investigation. Section 3 presents the estimation strategy adopted, provides some tests of the validity of RDD and discusses estimation results. In Section 4 some robustness checks are carried out. Section 5 concludes.

\section{Background and Descriptive Statistics}

The Italian University system is organized around three main levels: First Level Degrees (3 years of legal duration), Second Level Degrees (2 years more) and Ph.D. Degrees. In order to gain a First Level Degree students have to acquire a total of 180 credits. Students who have acquired a First Level Degree can undertake a Second Level Degree (acquiring 120 more credits). After having accomplished their Second Level Degree, students can enroll in a Ph.D. degree.

Italian Universities are required to test freshmen students' skills in relation to the requirements necessary for the chosen degree course. Students who do not meet a minimum required level of skills have to undertake educational processes enabling them to start academic courses with an adequate level of skills. At the purpose of helping students to reach this level, many Italian Universities, at the beginning of each academic year, organize a number of courses at pre-university level, which typically focus on mathematics and language skills. 
Notwithstanding the widespread adoption of remedial courses, their effectiveness has never been investigated. Often such kind of programs are decided at faculty or department level and it is difficult to get data on placement rules and on students' characteristics and outcomes.

In this work we take advantage of a project, financed by the European Social Fund, involving 4,019 students enrolled in the academic year 2009-10 at the University of Calabria, a medium sized Public University located in the South of Italy. The project was aimed at improving students' basic competences through an intensive training program offering a number of courses in subjects such as mathematics and language skills.

Students participating at the project were asked to take a placement test (with multiple choice questions), before the start of the educational activities (in September 2009). Students were tested to determine whether they were able to meet a given level of academic proficiency that was defined autonomously by each field of study. We have data on 5 different fields of study offered at the University of Calabria: Economics (31\% of students), Pharmacy (15\%), Humanities (24\%), Mathematics and Natural Sciences (15\%), Political Sciences $(15 \%){ }^{3}$ In each field of study, students performing below a certain cutoff score were required to enroll in the remedial courses.

We build a variable, Test Score $_{i}$, as the percentage of correct answers given by student $i$ in the placement test and to make homogeneous students' scores across fields of study we subtract the threshold level fixed by each faculty to assign students to remediation. In this way, a score of +1 indicates that the student is placed just above the threshold and he/she is not required to attend the remedial courses, while a score of 0 or a negative score indicate that the student is below the threshold and must attend the remedial courses. We define the dummy variable Assigned Treatment, which takes the value of one if student $i$ has been assigned to the remedial courses ( Test $\left._{\text {Score }} \leq 0\right)$ and zero otherwise.

There was a single placement test and students were not allowed to retake the test. As a consequence, differently from other studies examining remedial courses in US, we do not have to deal with problems deriving from the fact that unobserved factors may influence the likelihood of passing the remedial cutoff after retesting.

Remedial courses began in the first week of September 2009 and have lasted about 2 months for a total of 160 teaching hours covering mathematical and language skills. It is worthwhile to note that a standard college-level course typically consists of 60 hours and therefore the investments in teaching activities and student time has been considerable. Remedial courses do not confer academic credits. Students assigned to treatment were highly recommended to attend the courses, but attendance was not compulsory. We build the variable Effective Treatment $_{i}$ as the number of hours of remedial

\footnotetext{
${ }^{3}$ We have decided to exclude from our analysis students enrolled in Engineering because all the students in this field, independently from the Test Score obtained, were highly recommended to attend the remedial courses.
} 
courses attended by student $i$. College courses for all the students started only after the ending of the remedial courses.

Thanks to the administrative data provided by the University of Calabria we have detailed information on all the students enrolled at the University of Calabria in the academic year 2009-10. We observe a number of individual characteristics such as gender, province of residence, year of high school accomplishment and some measures of ability (High School Grade and type of High School attended).

As shown in Table 1, reporting descriptive statistics, $61 \%$ of students were assigned to remedial courses (Assigned Treatment). However, participation to the treatment was only partial: the average number of hours of remedial courses attended by students assigned to the treatment was 81 (out of 160) while the average of Effective Treatment for the whole sample is equal to 50; only about $34 \%$ of the sample has participated to at least $80 \%$ of the total amount of lectures (in hours) provided within the remedial program (Treatment: $80 \%$ of hours).

Females are about $65 \%$ of the sample, High School Grade is on average 82, ranging from 60 to $100,49 \%$ of students attended a Lyceum (instead of a technical or vocational school) and about $24 \%$ of them enrolled at University not in the same year in which they graduated from High School (Late Enrolment).

By the end of their second year of degree program students have acquired about 46 credits (out of 120 that they were expected to earn) and $23 \%$ of them are at strong risk of dropping out since they have acquired zero credits. The average grade at passed exams is 24 (exams are evaluated on a scale ranging from 18 (the minimum passing line) to 30 cum laude (31)). 
Table 1. Descriptive Statistics

\begin{tabular}{lccccc}
\hline \hline Variable & Obs & Mean & Std. Dev. & Min & Max \\
\hline Assigned Treatment & 4019 & 0.608 & 0.488 & 0 & 1 \\
Effective Treatment & 4019 & 49.813 & 62.553 & 0 & 160 \\
Treatment: 80\% of hours & 4019 & 0.342 & 0.474 & 0 & 1 \\
Test Score & 4019 & -1.978 & 14.796 & -50 & 46.835 \\
Credits & 4019 & 46.369 & 38.759 & 0 & 126 \\
Drop-out & 4019 & 0.237 & 0.426 & 0 & 1 \\
Average Grade & 3013 & 23.931 & 2.710 & 18 & 30 \\
Female & 4019 & 0.647 & 0.478 & 0 & 1 \\
High School Grade & 4019 & 81.586 & 11.616 & 60 & 100 \\
Lyceum & 4019 & 0.487 & 0.500 & 0 & 1 \\
Late Enrolment & 4019 & 0.238 & 0.426 & 0 & 1 \\
Field: Economics & 4019 & 0.307 & 0.461 & 0 & 1 \\
Field: Pharmacy & 4019 & 0.152 & 0.359 & 0 & 1 \\
Field: Humanities & 4019 & 0.239 & 0.427 & 0 & 1 \\
Field: Math and Sciences & 4019 & 0.150 & 0.357 & 0 & 1 \\
Field: Political Sciences & 4019 & 0.152 & 0.359 & 0 & 1 \\
\hline \hline
\end{tabular}

\section{The Effects of Remedial Courses on Student Achievement through a Fuzzy Regression Discontinuity Design}

To recover the causal effect of remedial courses on student performance we use a Fuzzy Regression Discontinuity Design exploiting the fact that the assignment to the treatment has been defined as a discontinuous function of the Test Score obtained by the student at the placement test (a student is assigned to remedial courses if his/her Test Score is zero or below). Even if the test score is correlated to student academic achievement, the relationship should be smooth with no jump in the proximity of the cutoff.

While in the sharp Regression Discontinuity Design treatment is defined deterministically by the fact that the forcing variable is below or above a certain threshold, in our context compliance of students to the assignment was not perfect: on the one hand, some of the subjects assigned to the treatment have decided to not participate to the educational program ("no-shows"); on the other hand, few students who were assigned to the "control group" (that is, remediation courses were not necessary as their Test Score was above the threshold) shifted to the treatment group by deciding to attend the remedial courses. Therefore, since the effective participation to the remedial courses is potentially related to observable and unobservable determinants of students' achievement, the estimates might be inconsistent.

To deal with endogeneity problems arising from partial compliance, as standard in the literature, we follow an Instrumental Variable estimation strategy using the exogenous assignment to 
the treatment as an instrument for the effective participation in the remedial courses. Therefore, we use a Fuzzy Regression Discontinuity Design in which the treatment status is probabilistically determined as a discontinuous function of the Test Score (Lee and Lemieux, 2010; Angrist and Pischke, 2009). Following most of the papers in the literature, we use a parametric approach.

Formally, we estimate the following model:

$$
\begin{aligned}
& Y_{i}=\beta_{0}+\beta_{1} \text { EffectiveTreatment }_{i}+\beta_{2} f\left(\text { Test } \text { Score }_{i}\right)+\beta_{3} X_{i}+\mu_{k}+\varepsilon_{i} \\
& \text { EffectiveTreatment }=\phi_{0}+\phi_{1} \text { AssignedTreatment }+\phi_{2} g\left(\text { Test Score }{ }_{i}\right)+\phi_{3} X_{i}+\mu_{k}+v_{i}
\end{aligned}
$$

where $Y_{i}$ is the performance of student $i$ (measured as the number of credits earned, the probability of drop-out and the average grade at exams); as explained in section 2, Effective Treatment is a variable measuring the number of hours of remedial courses attended (in some specifications we use, alternatively, a dummy variable taking the value of one when the student has attended at least the $80 \%$ of hours of remedial courses $) ; f\left(\right.$ Test Score $\left._{i}\right)$ and $g\left(\right.$ Test Score $\left._{i}\right)$ are two flexible functional forms relating Test Score, respectively, to academic outcomes and participation to Effective Treatment; $X_{i}$ is a vector of individual characteristics (gender, High School Grade, Lyceum, province of residence, Late Enrollment), which we use to increase the precision of estimates; $\mu_{k}$ are field dummies to take into account any difference across fields; $\varepsilon_{i}$ and $v_{i}$ are random error terms.

Equation [2] represents the first stage of the relationship between the student effective participation to remedial courses and the score obtained at the placement test. We use Assigned Treatment as an instrument for the number of hours attended. The parameter $\phi_{1}$ is the effect of the Assigned Treatment on the effective participation in the remedial courses.

Equation [1] shows that student achievement is related to Test Score, since students with higher abilities tend to perform well both at the placement test and in the following academic activities. However, the relationship between Test Score and academic achievement can be estimated using a smooth function. Under the assumption that the relationship between the outcome variable and Test Score is continuous in a neighborhood of the cutoff, any jump in the dependent variable in proximity of the cutoff point can be interpreted as evidence of a treatment effect. Therefore, the parameter $\beta_{1}$ measures the causal impact of remedial courses on student performance.

In what follows we will firstly discuss the main assumptions on which our estimation strategy relies and then present our main results. 


\subsection{Checks for Random Assignment Around the Discontinuity}

The crucial assumption underlying the RDD approach is that unobservable characteristics do not vary discontinuously around the cutoff and the cutoff rule provides exogenous variations in the treatment "as good as a randomized experiment".

This could not be the case if students behave in order to change their score near the cut-off. For example, students may purposely miss many test questions because they want to attend the remedial course or, alternatively, they may retake the placement test in order to obtain a better result and avoid the remedial courses. However, in our setting since students do not know in advance the threshold level necessary to pass the test, it is unlikely that they would be able to marginally change their score near the cutoff. Moreover, students were not allowed to retake the placement test. Therefore, the requirement that individuals must not have precise control over the assignment variable seems satisfied.

We carried out the formal test proposed by McCrary (2008) to investigate whether there is any discontinuity around the cutoff in the density of the assignment variable. The variable Test Score has been partitioned into equally spaced bins (of width 1$) ;{ }^{4}$ the frequency counts have been used as a dependent variable in a regression with a polynomial of Test Score (until the fourth order) and in a local linear regression. In these regressions the variable Assigned Treatment is never statistically significant, confirming the inexistence of a discontinuity at the cutoff.

The absence of manipulation is confirmed by the inspection of the graph below representing the density of the test score obtained by students at the placement test along with predicted values from a third-order polynomial model: since there is no discontinuity in the distribution of the test score at the cutoff we are reassured that this variable was not manipulated by students.

\footnotetext{
${ }^{4}$ The procedure is robust to the choice of different bandwidths.
} 


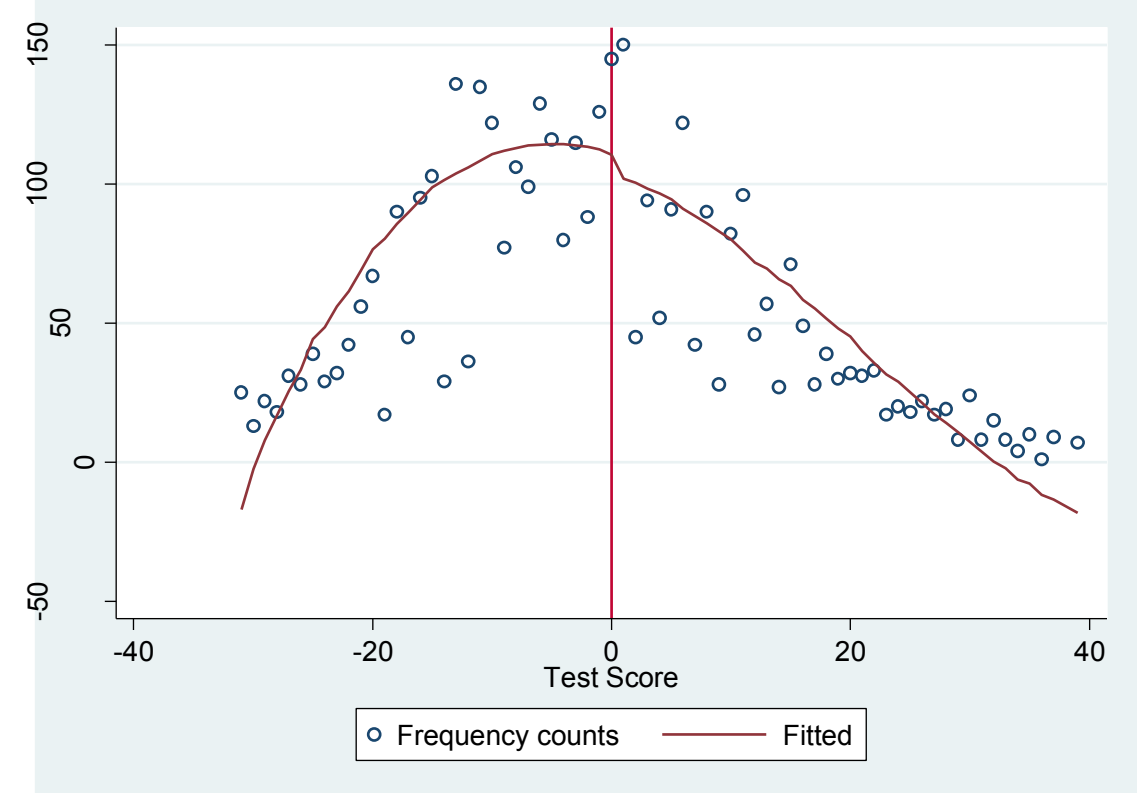

Figure 1. Density of the Forcing Variable (Test Score)

An additional requirement for the validity of RDD is that predetermined covariates balance for students just above and below the cutoff. In fact, in absence of manipulation, students around the threshold score should not differ significantly in terms of observable and unobservable variables. In Table 2 we report descriptive statistics on students' characteristics for, respectively, those who scored below and above the cutoff. As shown in Table 2, students' characteristics are significantly different for the two groups when we consider the whole sample, but the differences tend to vanish when we compare students within a small range around the cutoff. This reassures us about the random assignment around the discontinuity point (Imbens and Lemieux, 2008). Since not all variables are balanced, to avoid any bias due to the lack of balance we control for these variables in the regressions.

Table 2. Differences in predetermined characteristics Below and Above Cutoff

\begin{tabular}{|c|c|c|c|c|c|c|c|c|c|}
\hline Variable & Above & Below & Difference & Above & Below & Difference & Above & Below & Difference \\
\hline & \multicolumn{3}{|c|}{ ALL } & \multicolumn{3}{|c|}{ Bandwidth $+10 /-10$} & \multicolumn{3}{|c|}{ Bandwidth $+5 /-5$} \\
\hline Female & 0.596 & 0.680 & $-0.083^{* * *}$ & 0.604 & 0.665 & $-0.061 * * *$ & 0.610 & 0.652 & -0.042 \\
\hline High School Grade & 85.560 & 79.022 & $6.538 * * *$ & 83.479 & 80.440 & $3.038 * * *$ & 82.771 & 81.500 & 1.271 \\
\hline Lyceum & 0.608 & 0.410 & $0.198 * * *$ & 0.506 & 0.463 & 0.043 & 0.489 & 0.510 & -0.022 \\
\hline Late Enrolment & 0.216 & 0.252 & $-0.036 * * *$ & 0.238 & 0.241 & -0.002 & 0.224 & 0.236 & -0.012 \\
\hline Field: Economics & 0.296 & 0.315 & -0.019 & 0.343 & 0.337 & 0.006 & 0.338 & 0.340 & -0.001 \\
\hline Field: Pharmacy & 0.098 & 0.187 & $-0.089 * * *$ & 0.115 & 0.129 & -0.014 & 0.130 & 0.094 & 0.036 \\
\hline Field: Humanities & 0.319 & 0.187 & $0.131 * * *$ & 0.225 & 0.255 & -0.031 & 0.219 & 0.300 & $-0.093 * * *$ \\
\hline Field: Sciences and Math & 0.169 & 0.137 & $0.032 * * *$ & 0.152 & 0.126 & 0.026 & 0.134 & 0.127 & 0.007 \\
\hline Field: Political Sciences & 0.118 & 0.174 & $-0.055^{* * *}$ & 0.165 & 0.153 & 0.012 & 0.177 & 0.127 & 0.051 \\
\hline Obs. & 1576 & 2443 & & 810 & 1245 & & 446 & 732 & \\
\hline
\end{tabular}

The symbol $* * *$ indicate that coefficients are statistically significant at the 1 percent level. 


\subsection{First Stage Results}

As explained above, in our setting assignment to the treatment, based on whether student performance was below a predetermined threshold, does not perfectly predict the actual participation in remediation courses.

Based on the First Stage Equation, in Figures 2 and 3 we plot, respectively, the number of hours of remedial courses attended (Effective Treatment) and the probability of attending at least the 80\% of the remedial courses (High Attendance) against the score obtained by students at the placement test.

In Figure 2, the circles are the mean of hours effectively attended for a given Test Score, while the connected points are the predicted values from the first stage equation. As it is possible to see in the left side of the graph in Figure 2, students below the cut-off have attended on average 81 hours of courses, while those above the cutoff have attended only 1.43 hours. Similarly, from Figure 3, the probability of attending at least the $80 \%$ of remedial activities for those who scored below the cutoff is 0.56 , while it reduces to just 0.01 for students scoring above the threshold.

These graphs make clear the essence of the fuzzy regression discontinuity design we adopt to estimate the effects of remedial courses, since it clearly emerges the discontinuous relationship between test scores and effective participation to remedial courses. Even if not all the students below the cutoff point attended the remedial courses, their probability of attendance is significantly higher than the probability of students scoring above the cutoff.

Thanks to the fact that the probability of treatment changes discontinuously at the cutoff, it is possible to determine the treatment effect in case of partial compliance by comparing mean outcomes of individuals in a narrow range on either side of the cutoff and scaling the difference in outcomes by the difference in the probability of treatment. 


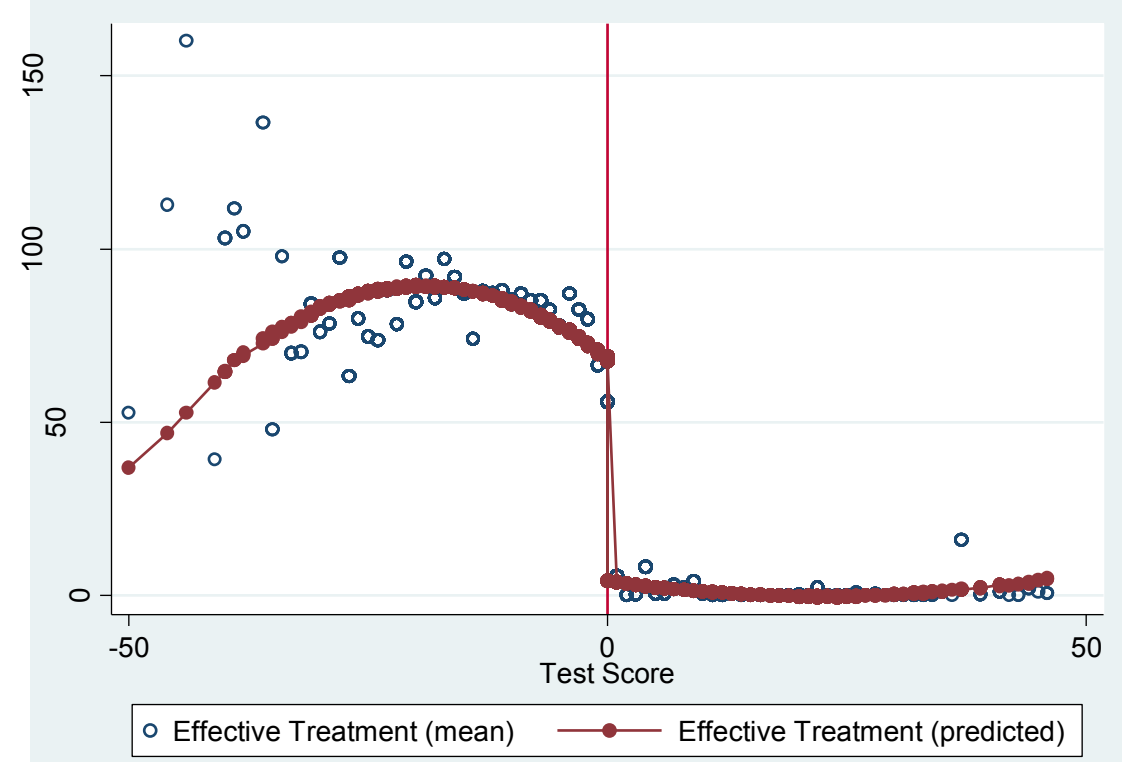

Figure 2. First Stage relationship: Test Score and Predicted Hours of remedial courses

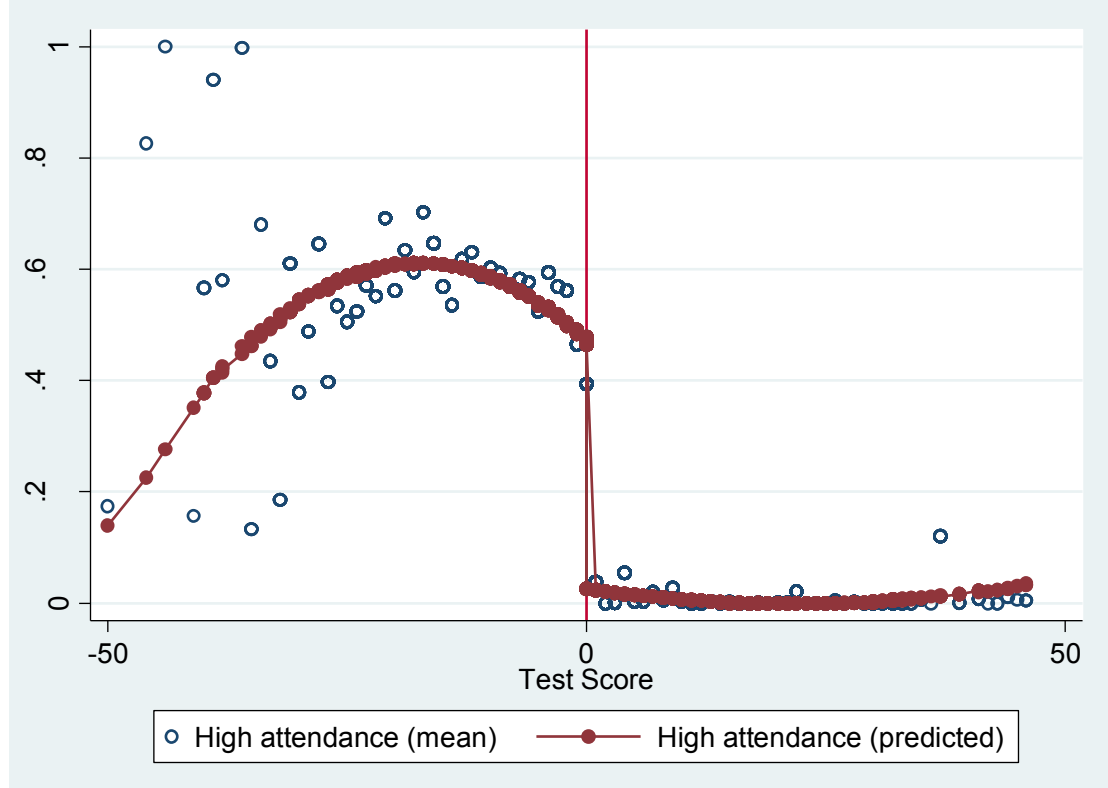

Figure 3. First Stage relationship: Test Score and Predicted Probability of $\mathbf{8 0 \%}$ of Attendance

\subsection{Estimation Results}

In this section we present our main results on the effects of remediation on student achievement. As outcome variables we use different measure of student performance. We focus on the number of 
credits obtained during the first two years of degree program and on the probability of dropping out, but we also provide evidence on the effects of remediation on the average grade at exams. ${ }^{5}$

In Table 3 are shown Two Stage Least Squares (TSLS) estimates, considering as dependent variable the number of Credits acquired by students. In the Panel B of the Table are reported First Stage estimation results. Standard errors are robust to heteroskedasticity. ${ }^{6}$

In order to choose a correct specification of $f\left(\right.$ Test $\left._{\text {Score }}\right)$ and $g\left(\right.$ Test $\left._{\text {Score }}\right)$ we have visually inspected the data and a quadratic or cubic specification generally provide a good fit. However, in the estimates reported in Table 3, to check the robustness of our results, we use different polynomial trends, from the first to the fourth order.

The First Stage confirms that, controlling for flexible functions of Test Score, the assigned treatment strongly determines the effective treatment: around the threshold, being assigned to the treatment leads to about 65-70 hours more of remedial courses (the First Stage $F$-statistics is always more than 500).

Considering the Second Stage, controlling for a polynomial of Test Score and for individual covariates and field dummies, it emerges that the effect of remedial courses is positive and statistically significant at the 1 or 5 percent level: the participation to 100 hours of remedial courses leads to an increase in the number of credits gained during the first two years ranging from 5.88 to 7.60 according to the polynomial form used. The estimates are rather stable with respect to changes in the polynomial of Test Score.

The estimated coefficients represents the average effect of remedial courses on those individuals who received treatment because they scored just below the cutoff in the placement test (Local Average Treatment Effect or LATE).

As expected, Test Score is positively and highly correlated to subsequent student performance. The effects of control variables are consistent with the findings emerging from the literature. Students with a higher High School Grade obtain a much better academic performance. In addition, students who attended a Lyceum perform better than students who come from Technical or Vocational Schools. The dummy Female is always positive and statistically significant.

Very similar results are obtained when we measure Effective Treatment with the dummy variable taking value of one for students attending at least $80 \%$ of remedial courses (132 hours). Having attended to the $80 \%$ of the remedial activities leads to an increase in the number of credits acquired ranging from 8.27 to 10.86 (not reported).

\footnotetext{
${ }^{5}$ Unfortunately we do not have information on long term outcomes, such as the probability of obtaining the degree or labour market outcomes.

${ }^{6}$ We have also experimented clusterizing standard errors at the Test Score level. Results are very similar to those shown and are not reported.
} 
As the policy-maker is more interested in knowing the expected benefits of the program on the subjects targeted by the program, in Panel C of Table 3 we report the intention-to-treat (ITT) effects (Heckman, LaLonde and Smith, 1999). To recover the ITT effects we use a Sharp Regression Discontinuity Design, in which the treatment status is simply defined by the placement rule (Imbens and Lemieux, 2008; Angrist and Pischke, 2009), which corresponds to the reduced form of our model (equations 1 and 2). The estimates show that being assigned to the treatment, consisting in 160 hours of teaching activities, determines an increase ranging from 4.08 to 4.88 credits. To compare this figure with the Local Average Treatment Effect, consider that the assignment to a remedial course of 100 hours would determine an increase of student credits ranging from 2.50 to 3.05 according to the specification considered.

Table 3. Fuzzy Regression Discontinuity Estimates of Remedial Course on Credits. TSLS Estimates. Full Sample.

$(1) \quad(2) \quad(3) \quad(4)$

Panel A: Two-Stage Least Squares Estimates

\begin{tabular}{|c|c|c|c|c|}
\hline Effective Treatment & $\begin{array}{c}0.0588 * * \\
(0.0254)\end{array}$ & $\begin{array}{c}0.0679 * * * \\
(0.0254)\end{array}$ & $\begin{array}{c}0.0760 * * \\
(0.0328)\end{array}$ & $\begin{array}{l}0.0742 * * \\
(0.0328)\end{array}$ \\
\hline Test Score & $\begin{array}{c}0.4996 * * * \\
(0.0762)\end{array}$ & $\begin{array}{c}0.5230 * * * \\
(0.0757)\end{array}$ & $\begin{array}{c}0.5729 * * * \\
(0.1412)\end{array}$ & $\begin{array}{r}0.5668 * * * \\
(0.1413)\end{array}$ \\
\hline Female & $\begin{array}{c}6.0165 * * * \\
(1.1796)\end{array}$ & $\begin{array}{c}6.1293 * * * \\
(1.1756)\end{array}$ & $\begin{array}{c}6.1448 * * * \\
(1.1751)\end{array}$ & $\begin{array}{r}6.1458 * * * \\
(1.1751)\end{array}$ \\
\hline High School Grade & $\begin{array}{c}0.9477 * * * \\
(0.0538)\end{array}$ & $\begin{array}{c}0.9335 * * * \\
(0.0540)\end{array}$ & $\begin{array}{c}0.9277 * * * \\
(0.0556)\end{array}$ & $\begin{array}{c}0.9291 * * * \\
(0.0556)\end{array}$ \\
\hline $\begin{array}{l}\text { Lyceum } \\
(\text { Test Score })^{2}\end{array}$ & $\begin{array}{l}7.4451^{* * *} \\
(1.1296)\end{array}$ & $\begin{array}{c}7.3429 * * * \\
(1.1305) \\
0.0078 * * *\end{array}$ & $\begin{array}{c}7.3411 * * * \\
(1.1307) \\
0.0079 * * *\end{array}$ & $\begin{array}{c}7.3579 * * * \\
(1.1306) \\
0.0059\end{array}$ \\
\hline$(\text { Test Score })^{3}$ & & $(0.0017)$ & $\begin{array}{l}(0.0018) \\
-0.0000\end{array}$ & $\begin{array}{l}(0.0040) \\
-0.0000\end{array}$ \\
\hline$(\text { Test Score })^{4}$ & & & $(0.0001)$ & $\begin{array}{c}(0.0001) \\
0.0000\end{array}$ \\
\hline Observations & 4019 & 4019 & 4019 & $\begin{array}{c}(0.0000) \\
4019\end{array}$ \\
\hline \multicolumn{5}{|c|}{ Panel B: First Stage } \\
\hline Assigned Treatment & $\begin{array}{c}69.498 * * * \\
(2.348)\end{array}$ & $\begin{array}{l}69.590 * * * \\
(2.253)\end{array}$ & $\begin{array}{c}64.257 * * * \\
(2.818)\end{array}$ & $\begin{array}{c}\text { 64.851*** } \\
(2.725)\end{array}$ \\
\hline R-squared & 0.444 & 0.444 & 0.445 & 0.446 \\
\hline $\begin{array}{l}\text { First-Stage F-statistics } \\
p \text {-value }\end{array}$ & $\begin{array}{c}875.945 \\
0.000\end{array}$ & $\begin{array}{c}953.694 \\
0.000\end{array}$ & $\begin{array}{c}520.058 \\
0.000\end{array}$ & $\begin{array}{c}566.549 \\
0.000\end{array}$ \\
\hline
\end{tabular}

Panel C: Intention To Treat Effects

\begin{tabular}{lcccc}
\hline Assigned Treatment & $4.0873 * *$ & $4.7282^{* * *}$ & $4.8808^{* *}$ & $4.8131^{* *}$ \\
& $(1.7792)$ & $(1.7791)$ & $(2.1257)$ & $(2.1400)$ \\
\hline \hline
\end{tabular}

Notes: The Table reports IV estimates. The dependent variable is Credits. In all regressions we control for field of studies dummies, province dummies and Late Enrolment. Standard errors (corrected for heteroskedasticity) are reported in parentheses. The symbols $* * *, * *, *$ indicate that coefficients are statistically significant, respectively, at the 1,5 , and 10 percent level. 
These estimates suggest that remediation has positive effects on the number of credits acquired by students. The effect is not particularly large, but it has to be considered that the average number of credits acquired by students in two years (46.3) is quite small too.

It could also be that the remedial program has produced a stronger impact on those students who are more in need of support. To investigate this aspect, instead of considering as a measure of performance the number of credits gained, we focus on the probability of dropping out from university. Although we do not have direct information on whether students have decided to drop out of their university studies, we consider students who have gained zero credits during the first two years of degree program as students who have dropped-out or who are at strong risk of dropping out. Then, we use this information to define a dummy variable Drop-out that takes the value of one when the student has not passed any exam during the first and the second year of his/her academic career and 0 otherwise.

For the sake of simplicity, we estimate a Linear Probability Model for Drop-out (estimation results are in Table 4), replicating the specifications reported in Table 3. The First Stage is identical to the estimation of Table 3. From TSLS estimates it emerges that students attending 100 hours of remedial courses have a lower probability of dropping out ranging from 7 to 8 percentage points, statistically significant at the 5 percent level in all the specifications. Since the probability of dropping out for our sample students is of about $24 \%$, the remedial program effect implies a reduction in the probability of drop-out of about $29 \%-33 \%$.

The intention to treat effect (shown in the second panel of the Table 4) is, as expected, smaller, but still very relevant: the assignment to the treatment determines a reduction in the probability of dropping out ranging from 4.68 to 5.37 percentage points or, equivalently, the assignment to a course of 100 hours leads to a reduction of drop-out probability from 2.92 to 3.29 percentage points. The ITT effect is statistically significant at the 5 percent level. 
Table 4. Fuzzy Regression Discontinuity Estimates of Remedial Course on Drop-out. TSLS Estimates. Full Sample.

\begin{tabular}{llll}
$(1)$ & $(2)$ & $(3)$ & $(4)$ \\
\hline
\end{tabular}

Two-Stage Least Squares Estimates

\begin{tabular}{|c|c|c|c|c|}
\hline Effective Treatment & $\begin{array}{c}-0.0007 * * \\
(0.0003)\end{array}$ & $\begin{array}{c}-0.0007 * * \\
(0.0003)\end{array}$ & $\begin{array}{c}-0.0008 * * \\
(0.0004)\end{array}$ & $\begin{array}{c}-0.0008 * * \\
(0.0004)\end{array}$ \\
\hline Polynomial of Test Score & First order & Second order & Third order & Fourth order \\
\hline \multicolumn{5}{|c|}{ Intention To Treat Effects } \\
\hline Assigned Treatment & $\begin{array}{c}-0.0468 * * \\
(0.0214)\end{array}$ & $\begin{array}{c}-0.0490 * * \\
(0.0213)\end{array}$ & $\begin{array}{c}-0.0513 * * \\
(0.0260)\end{array}$ & $\begin{array}{c}-0.0527 * * \\
(0.0258)\end{array}$ \\
\hline Observations & 4019 & 4019 & 4019 & 4019 \\
\hline
\end{tabular}

One of the main advantage of the Regression Discontinuity Design is that it allows to visually identify the treatment effect. In Figure 4 (panel a: Credits; panel b: Drop-out) we show the intention to treat effects, which are more relevant from a policy point of view. The circles represent the mean of the dependent variables for students with a given Test Score level. In the Figure are represented the predicted values from a model explaining Credits and Drop-out probability in relation to the Assigned Treatment, controlling for a quadratic function of Test Score (specification 2 of Table 3 and Table 4, respectively). The vertical line at the value of zero of the Test Score denotes the cut-off defined by the assignment rule.

In panel (a) of Figure 4, it emerges a jump in the relationship between the Credits and the Test Score in the proximity of the cut-off point: students assigned to the treatment (just below the cutoff) earn more credits than students just above the cutoff. Although the jump is statistically significant, it is rather modest in magnitude: about 4.7 credits more for students assigned to the treatment (corresponding to about 0.12 standard deviations of Credits).

The jump is quite clear also when inspecting the conditional mean of the dropping out probability around the cut-off (panel b). As shown above, the impact of remedial courses on this outcome variable is larger, suggesting that remedial courses have positively affected especially students more in need of help. 

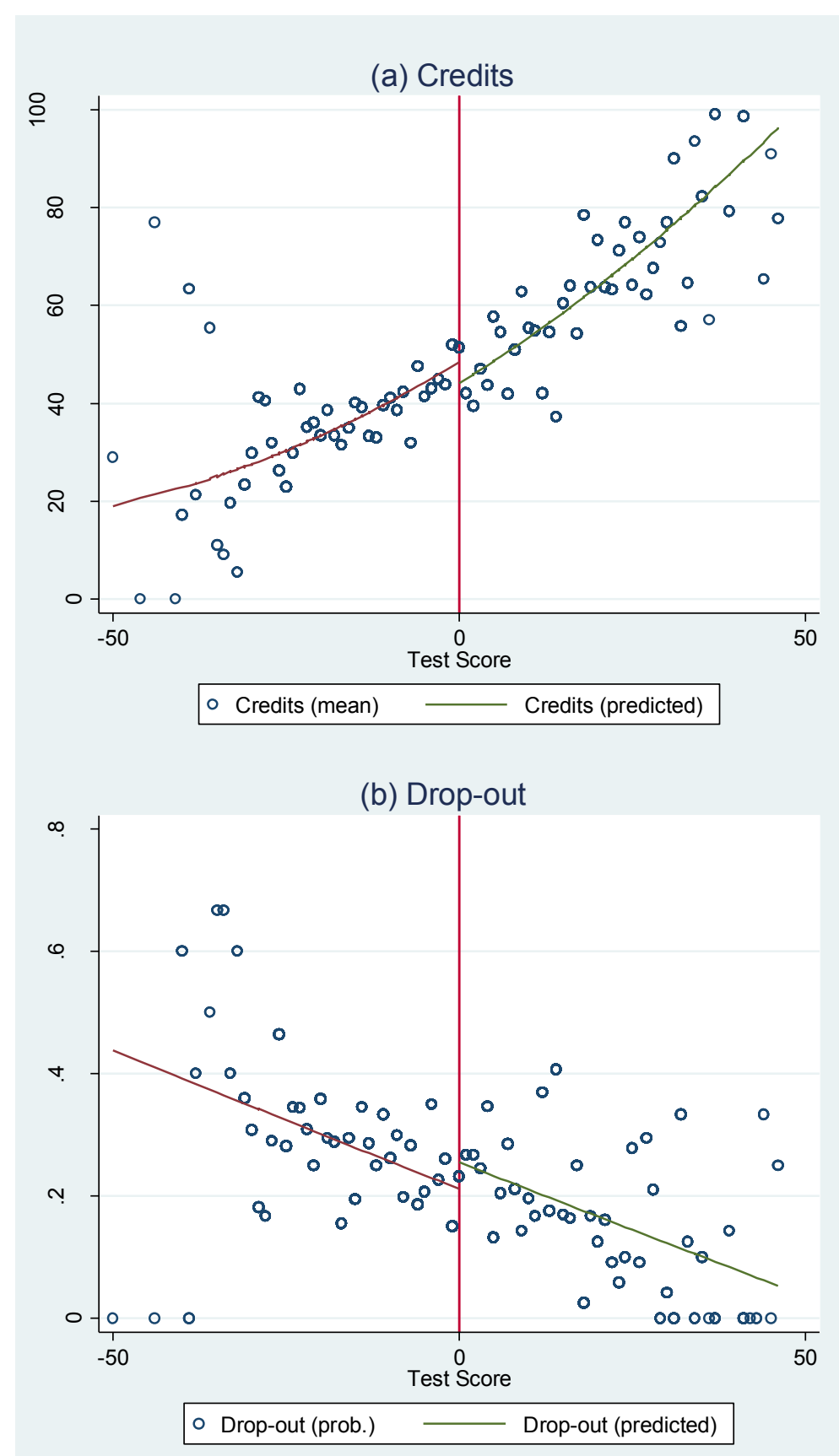

Figure 4. Intention to Treat Effects. (a) Credits and Test Score (b) Probability of Drop-out and Test Score

Finally, we investigate if remedial courses have on impact on the average grade students obtained at passed exams. In our sample, 3,013 students have passed at least one exam in the two years considered and for them it is possible to calculate the average grade. We estimate the same specifications as in Table 3. However, as shown in Table 5, we do not find any statistically significant effect of remedial courses on the average grade at exams controlling for different polynomial orders of Test Score. 
A possible explanation is that remediation - as shown above - allows a larger number of students to pass the exams and the positive effect appears stronger for low ability students at risk of dropping-out. Students pass the exam when they reach the minimum passing line (18) and since the remedial program has increased the number of students reaching the line, this translates in a reduction of the average grade obtained at exams.

Table 5. Fuzzy Regression Discontinuity Estimates of Remedial Course on the Average Grade. TSLS Estimates. Full Sample.
(1)
(2)
(3)
(4)

Two-Stage Least Squares Estimates

\begin{tabular}{lcccc}
\hline & & & & \\
Effective Treatment & -0.0003 & -0.0001 & 0.0016 & 0.0016 \\
& $(0.0016)$ & $(0.0016)$ & $(0.0021)$ & $(0.0021)$ \\
Polynomial of Test Score & First order & Second order & Third Order & Fourth Order \\
\hline
\end{tabular}

Intention To Treat Effects

\begin{tabular}{lcccc}
\hline Assigned Treatment & -0.0255 & -0.0044 & 0.1122 & 0.1092 \\
& $(0.1244)$ & $(0.1234)$ & $(0.1474)$ & $(0.1478)$
\end{tabular}

\begin{tabular}{lllll}
\hline Observations & 3013 & 3013 & 3013 & 3013 \\
\hline \hline
\end{tabular}

Notes: The Table reports IV estimates. The dependent variable is Average Grade. In all regressions we control for field of studies dummies, province dummies and individual characteristics (see Table 3). Standard errors (corrected for heteroskedasticity) are reported in parentheses. The symbols $* * *, * *, *$ indicate that coefficients are statistically significant, respectively, at the 1,5 , and 10 percent level.

\section{Robustness checks}

In this section we check the robustness of our results firstly including interaction terms between treatment and polynomials of Test Score and, secondly, considering only data in a neighborhood around the discontinuity (Local Linear Regression).

Firstly, in order to not impose any restriction on the underlying conditional forms, we include among controls interaction terms between the polynomial terms of Test Score and Effective Treatment and use as instrumental variables the interactions between Assigned Treatment and $g\left(\right.$ Test Score $\left._{i}\right)$. This procedure corresponds to estimating separate functions on either side of the cutoff.

In Table 6 (First Stage results are not reported to save space), it emerges that estimates of our parameter of interest turn out to be similar to those presented above, but the effects become larger in magnitude when the polynomial order increases. In all the specifications, the effect of remedial courses on the number of credits gained by students is positive and statistically significant (columns 1$3)$. 
In columns (4)-(6) are reported the effects of remedial courses on the probability of droppingout. Using these specifications, we are able to confirm that remedial courses significantly reduce the probability of drop-out.

On the other hand, no statistically significant effect emerges on the probability of dropping out from university studies.

Table 6. Fuzzy Regression Discontinuity Estimates of Remedial Course on the Number of Credits and on Drop-out. TSLS Estimates. Full Sample. Polynomial with Interactions.

\begin{tabular}{cccccc}
\hline \hline$(1)$ & $(2)$ & $(3)$ & $(4)$ & $(5)$ & $(6)$ \\
Credits & Credits & Credits & Drop-out & Drop-out & Drop-out \\
\hline
\end{tabular}

Two-Stage Least Squares Estimates

\begin{tabular}{lllllll}
\hline Effective Treatment & $\begin{array}{l}0.0709 * * * \\
(0.0254)\end{array}$ & $\begin{array}{l}0.0842 * * \\
(0.0370)\end{array}$ & $\begin{array}{l}0.1974 * * * \\
(0.0615)\end{array}$ & $\begin{array}{l}-0.0007 * * \\
(0.0003)\end{array}$ & $\begin{array}{l}-0.0009 * * \\
(0.0005)\end{array}$ & $\begin{array}{l}-0.0031^{* * *} \\
(0.0010)\end{array}$ \\
& & & & & & \\
Polynomial Term & First order & Second order & Third order & First order & Second order & Third order \\
\hline Observations & 4019 & 4019 & 4019 & 4019 & 4019 & 4019 \\
\hline \hline
\end{tabular}

Notes: The Table reports IV estimates. The dependent variable is Credits in columns 1-3 and Drop-out in columns 4-6. In all regressions we control for field of studies dummies, province dummies and individual characteristics (see Table 3). Standard errors (corrected for heteroskedasticity) are reported in parentheses. The symbols $* * *, * *, *$ indicate that coefficients are statistically significant, respectively, at the 1,5 , and 10 percent level.

As a further robustness check we present estimation results obtained using a local linear regression (LLR) approach, considering only the observations in a neighborhood around the discontinuity (Angrist and Pischke, 2009; Lee and Lemieux, 2010). The comparison of average outcomes in a small enough neighborhood to the left and to the right of the threshold value should estimate the effect of interest in a way that does not depend on the correct specification of the model for the conditional expected function.

Using the cross-validation procedure suggested by Lee and Lemieux (2010) to choose the optimal bandwidth, it emerges that the cross-validation function declines initially but it becomes fairly flat after about 10 points of Test Score. Then, we experiment focusing on three different bandwidths considering respectively students with a score ranging from -10 to +10 points around the cut-off, $-7 /+7$ and $-5 /+5$. Following the literature, we only use a linear function of Test Score instead of higher order polynomials when dealing with these narrow windows.

In Table 7 are reported results from our local linear regressions. The estimates barely change in terms of statistical significance but become larger in magnitude. In all specifications, remedial courses produce an increase in the number of credits acquired (columns 1,2 and 3) and the effect becomes larger in magnitude as the score interval is shortened. Consistently with previous results we also find that remedial courses reduce the probability of dropping out from university studies (columns $4-6)$. 
However, local linear estimates show no impact when we consider as dependent variable the average grade at passed exams.

Table 7. Fuzzy Regression Discontinuity Estimates of Remedial Course on Credits and Dropout. Local Linear Regressions. Different Windows.

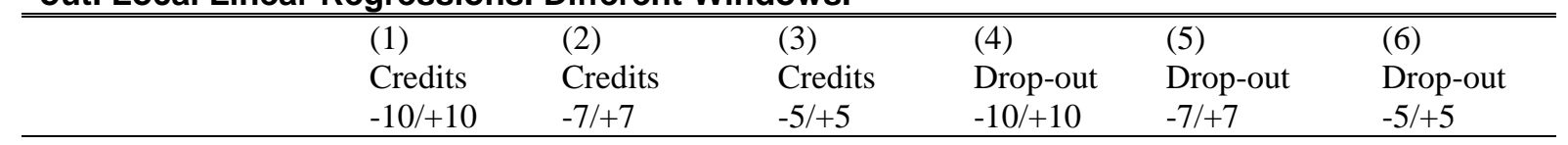

Two-Stage Least Squares Estimates

\begin{tabular}{lllllll} 
Effective Treatment & $\begin{array}{l}0.1013^{* *} \\
(0.0492)\end{array}$ & $\begin{array}{l}0.1389^{* *} \\
(0.0604)\end{array}$ & $\begin{array}{l}0.1979^{* * *} \\
(0.0690)\end{array}$ & $\begin{array}{l}-0.0008 \\
(0.0006)\end{array}$ & $\begin{array}{l}-0.0012^{*} \\
(0.0007)\end{array}$ & $\begin{array}{l}-0.0020^{* *} \\
(0.0008)\end{array}$ \\
\hline Observations & 2055 & 1521 & 1178 & 2055 & 1521 & 1178 \\
\hline \hline
\end{tabular}

Notes: The Table reports IV estimates. The dependent variable is Credits in columns 1-3 and Drop-out in columns 4-6. In all regressions we use a linear function of Test Score and control for field of studies dummies, province dummies and individual characteristics (see Table 3). Standard errors (corrected for heteroskedasticity) are reported in parentheses. The symbols ***, **, * indicate that coefficients are statistically significant, respectively, at the 1,5 , and 10 percent level.

\section{Concluding Remarks}

While remedial courses are increasingly used by European Universities, little is known about their effects. Only recently a small literature on this topic is trying to handle with adequate estimation strategies the endogeneity problems that undermined the earlier evidence. These recent studies are all focused on the US experience and it is difficult to understand how the effects found are related to the specific features of the US educational system.

In this paper we have tried to shed some light on this issue providing an evaluation of remedial courses offered by an Italian University. To uncover the effects of remedial courses we have used a Fuzzy Regression Discontinuity Design relying on the fact that only students scoring at a placement test below a certain threshold value were required to attend the remedial program.

Compared to similar works investigating the effects of remediation in US, we take advantage of the fact that in our case remedial courses were not a pre-requisite to enroll in college level courses and students did not have incentives in trying to avoid to be placed under remediation. Moreover, students could not retake the placement test and, as a consequence, we did not face manipulation problems. Another interesting feature of our analysis is that we measure the intensity of the treatment rather precisely, as we know the exact number of teaching hours attended by each student. Finally, we had not to deal with the bias that may derive from the fact that students assigned to remediation may decide to undertake easier courses since our sample students were required to choose their subject of study before taking the placement test and, in addition, the courses of the first two years are compulsory. 
From our analysis it emerges that remedial courses have a positive impact on the number of credits acquired by students during the first two years of their academic career. The magnitude of the effect, ranging from 7 to 10 credits in most specifications, is not very large, if one considers the relevant investment of 160 hours in terms of teaching activities (and students' effort).

However, we find significantly larger effects as regards the probability of drop-out from university, which reduces of 7-8 percentage points for students attending remedial courses (a decrease of about $30 \%$ ), suggesting that remedial courses could have an impact especially on low ability students.

\section{References}

Angrist, J., Lavy, V., (1999), “Using Maimonides' rule to estimate the effect of class size on scholastic achievement", Quarterly Journal of Economics, 144, 533-576.

Angrist, J., Pischke, J., (2009), Mostly Harmless Econometrics, Princeton University Press.

Bettinger, E., and Long, B. (2009). Addressing the needs of under-prepared college students: Does college remediation work? Journal of Human Resources, 44, 3.

Calcagno, J. C. and Long, B. (2010), "The Impact of Postsecondary Remediation Using a Regression Discontinuity Approach: Addressing Endogenous Sorting and Noncompliance", Mimeo.

Heckman, J., Lalonde, R., Smith, R. (1999), The economics and econometrics of active labor market programs, Handbook of labor economics, Elsevier. Volume: 3, Issue: 2, pp. 1-73.

Imbens, G., and Lemieux, T. (2008), "Regression Discontinuity Designs: A Guide to Practice", Journal of Econometrics, 142(2), 615-635.

Jacob, B., \& Lefgren, L. (2004). Remedial education and student achievement: A regressiondiscontinuity analysis. Review of Economics and Statistics, 86(1), 226-244.

Lagerlöf, J. and Seltzer, A. (2009), "The Effects of Remedial Mathematics on the Learning of Economics: Evidence from a Natural Experiment", Journal of Economic Education, 40: 2, 115-137.

Lavy, V. and Schlosser, A., (2005), "Targeted Remedial Education for Underperforming Teenagers: Costs and Benefits", Journal of Labor Economics, v23, pp. 839-874.

Lee, D., and Lemieux, T., (2010), "Regression Discontinuity Designs in Economics", Journal of Economic Literature, 48, 2, pp. 281-355.

Martorell, P., and McFarlin, I. (2010). "Help or hindrance? The effects of college remediation on academic and labor market outcomes", Unpublished manuscript.

McCrary, J. (2008) "Manipulation of the Running Variable in the Regression Discontinuity Design: A Density Test", Journal of Econometrics, 142(2): 698-714. 